\title{
Improving Drilled Cuttings Lifting Using Polypropylene Beads in Water-Based Mud at Different Annular Mud Velocities
}

\author{
I. Ismail, M. D. U. Onuoha, A. R. Ismail, A. Piroozian, W. R. Wan Sulaiman, and S. M. Abbda
}

\begin{abstract}
An effective drilled cuttings lifting from the bottomhole to the surface improves drilling performance. The transportation of drilled cuttings becomes more challenging when drilling a high angle or horizontal well. A sufficiently high annular mud velocity is essential to prevent drilled cuttings from settling and forming stationary beds on the low side of a hole. This can cause several drilling problems such as high torque and drag, stuck pipe, etc. This problem has been addressed via an experimental work which studied the effect of annular mud velocities on drilled cuttings removal using water-based mud with polypropylene beads in vertical, deviated, and horizontal holes. It was accomplished using a $3.96 \mathrm{~m}$ long flow loop which comprised $50.8 \mathrm{~mm}$ transparent acrylic section with a simulated drill string. The annular mud velocity was varied from $0.27 \mathrm{~m} / \mathrm{s}$ to $1.06 \mathrm{~m} / \mathrm{s}$ at ambient condition. The experimental results showed that increase in annular mud velocity has improved hole cleaning, i.e., cuttings transport ratio experienced an improved performance in the turbulent flow than in laminar flow. The findings further demonstrated that the presence of polypropylene beads in water-based mud has contributed positively to the performance of drilled cuttings lifting in a vertical hole by $9 \%$ in a turbulent flow.
\end{abstract}

Index Terms-Annular drilling mud velocity, cuttings transport ratio, polyethylene beads, water-based mud, wellbore cleaning.

\section{INTRODUCTION}

A well designed drilling program can reduce rig time and drilling cost experienced by oil companies in their drilling activities to increase the oil and gas reserves. In practice, many unexpected drilling problems may be encountered which would affect the drilling performance, such as stuck pipe, high torque and drag, etc. These problems can be worsened by poor wellbore cleaning [1] which will negatively affect the presumed economic benefits during drilling a vertical, deviated, or horizontal well.

Based on the strength of this premise, it is imperative to comprehend the influential factors that affect drilled cuttings

Manuscript received December 3, 2015; revised May 12, 2016. The authors would like to express their gratitude to Universiti Teknologi Malaysia and the Malaysian Ministry of Higher Learning for funding the project via the Fundamental Research Grant Scheme (Vot 4F575).

I. Ismail, A. R. Ismail, A. Piroozian, W. R. Wan Sulaiman, and S. M. Abbda's are with Dept. of Petroleum Engineering, Universiti Teknologi Malaysia, 81310 UTM Johor Bahru, Malaysia (e-mail: issham@utm.my, razak@utm.my, alipiroozian@yahoo.com,_r-wan@utm.my, s.abbda@yahoo.com).

M. D. U. Onuoha is with College of Mechanical and Oil/Gas Transport Engineering, China University of Petroleum Beijing, China (e-mail: macdarlingtonu@yahoo.com). transport and the consequent hole cleaning so that a drilling process can be executed in an effective manner. Many experimental works on cuttings removal [2]-[5] have been conducted over the years and poor hole cleaning in drilled wells still remains one of the major problems affecting drilling operations. Therefore, a further experimental work to complement those research findings has been accomplished using polyethylene-based polymer beads, an inert material, in water-based mud to improve the cuttings transport capacity of water-based mud.

\section{EXPERIMENTAL SET-UP}

A flow loop was designed to simulate a wellbore at the Malaysia Petroleum Resources Corporation Institute for Oil and Gas, Universiti Teknologi Malaysia. The purpose was to perform a research work on cuttings removal using a $3.96 \mathrm{~m}$ long transparent test loop section at any angles between vertical and horizontal. A schematic view of the test facility is shown in Fig. 1.

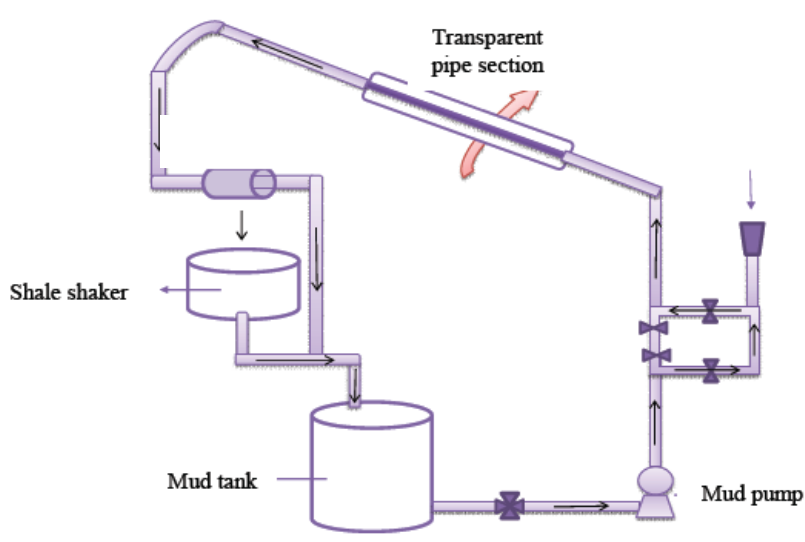

Fig. 1. Schematic view of the flow loop.

The flow loop consisted of $45.7 \mathrm{~mm}$ ID and $50.8 \mathrm{~mm}$ OD transparent acrylic outer pipe and a $20.3 \mathrm{~mm}$ OD hollow steel inner pipe. The inner pipe was sealed at both sides to avoid mud flow through it, installed at the center of the outer pipe, and was in a stationary state throughout the experimental work, i.e., no rotation for inner pipe throughout the test.

\section{EXPERIMENTAL PREPARATION}

Water-based mud was prepared by mixing the desired amount of bentonite and barite in tap water. The mud was mixed at a moderate shear rate using a mixer in the mud tank. Another mud sample was prepared, which comprised the 
polypropylene-based polymer beads (have regular sizes of 4 $\mathrm{mm}$ and are of spherical in shape with density $0.86 \mathrm{~g} / \mathrm{cc}$ ) to observe the variation in cuttings removal (cleaning) efficiency, as shown in Table I. Beach sands were used as drilled cuttings. They were cleaned, sieved, weighed, and packed in plastic bags of $170 \mathrm{~g}$ each. The sand particles had an irregular shape with size ranging from $1.5 \mathrm{~mm}$ to $1.8 \mathrm{~mm}$.

TABLE I: DRILLING MUD CHARACTERISTICS

\begin{tabular}{|c|c|c|c|}
\hline Mud Type & Component & $\begin{array}{l}\text { Density } \\
\text { (ppg) }\end{array}$ & $\begin{array}{l}\text { Viscosity } \\
\text { (cp) }\end{array}$ \\
\hline Basic mud & $\begin{array}{l}\text { Tap water }(350 \mathrm{ml}) \\
+ \text { Bentonite }(10 \mathrm{~g}) \\
+ \text { barite }(27.5 \mathrm{~g})\end{array}$ & 9 & 5 \\
\hline $\begin{array}{l}\text { Basic mud with } \\
\text { polymer beads }\end{array}$ & $\begin{array}{l}\text { Tap water }(350 \mathrm{ml}) \\
+ \text { bentonite }(8 \mathrm{~g})+ \\
\text { barite }(32 \mathrm{~g})+ \\
\text { polymer beads }(6 \mathrm{~g})\end{array}$ & ) & 5 \\
\hline
\end{tabular}

\section{EXPERIMENTAL PROCEDURE}

After the drilling mud has been formulated and mixed in the mud tank, it was circulated in the flow loop at the desired velocity for 3 minutes to achieve the stabilized flow velocity. Then the inlet valve was opened to allow the mud flowed through the cuttings inlet line. The experiment took 6 minutes for each run before the pump was turned off, and the lifted cuttings were collected from the shale shaker. Dried the collected cuttings, weighed and kept them in a separated plastic bag for each run. All of the steps were repeated for five different flow velocities (i.e., 0.27, 0.40, 0.67, 0.88, and $1.06 \mathrm{~m} / \mathrm{s}$ ). To forge ahead in the experiment, the above mentioned velocities was pursued using different angles, i.e., $0^{\circ}$ (vertical), $30^{\circ}, 50^{\circ}, 70^{\circ}$, and $90^{\circ}$ (horizontal). This trend was repeated till all experimental stages were fully implemented. The cutting transport ratio (CTR) of the mud sample with polymer beads was then compared with the CTR of basic mud. The CTR can be calculated using the following equation:

$$
\text { CTR }(\%)=\frac{\text { final cuttings weight } \times 100 \%}{\text { initial cuttings weight }}
$$

\section{RESUlTS AND DISCUSSION}

Effect of Annular Fluid Velocity. The experimental findings showed that velocity has positive contributions to stationary bed removal. The curves generated in Fig. 2(a) to (e) are found to be in good agreement with the results of other research works [2], [4], [6] — the increase in annular velocity produced a substantial increase in cuttings transport. The results also demonstrated that turbulent flow was more efficient in removing cuttings' beds than in the laminar flow. In turbulent flow, the shear stress applied onto the cuttings was found to be larger than in the laminar flow. To have a better understanding of the velocity effect on water-based mud with polymer beads, a comparison has been made between the CTR of basic drilling mud and CTR of drilling mud with polymer beads at various inclination angles, i.e., $0^{\circ}$ (vertical), $30^{\circ}, 50^{\circ}, 70^{\circ}$, and $90^{\circ}$ (horizontal) and at different annular mud velocities of $0.27 \mathrm{~m} / \mathrm{s}, 0.4 \mathrm{~m} / \mathrm{s}, 0.67 \mathrm{~m} / \mathrm{s}, 0.88$ $\mathrm{m} / \mathrm{s}$, and $1.06 \mathrm{~m} / \mathrm{s}$. The comparison shows an improvement in drilled cuttings removal using drilling mud with polymer beads for all the annular mud velocities at those inclination angles. It increased the CTR by 5\% for laminar flow and $9 \%$ for turbulent flow as compared to basic water-based mud.

Effect of Hole Inclination. The experimental results demonstrated that well inclination plays a key role in transporting drilled cuttings to the surface. This proves that hole cleaning is more demanding in directional wells management than in vertical wells. Fig. 3 illustrates the effect of hole inclination on hole cleaning where those curves represent different annular velocities of drilling mud with polymer beads. The distance between lines shows the velocity effect on the CTRs at five different angles, namely $0^{\circ}$ (vertical) $30^{\circ}, 50^{\circ}, 70^{\circ}$, and $90^{\circ}$ (horizontal). All the lines produce a downward trend by diverging from vertical, indicating that CTR has declined. Generally, the experimental results are found to be in good agreement with the published results by several researchers [2], [5], [7]. They highlighted that by increasing the hole inclination while keeping other parameters constant would dramatically reduce the carrying capacity of drilling fluids.

The best cuttings lifting performance was found to have occurred in the vertical hole. But an increase in the hole inclination from vertical to horizontal has decreased the cuttings transport performance. This is due to the increase in drag force, as the hole diverging from vertical, which is parallel to the direction of the mud flow. It should also be noted that the effect of gravity has worsened the condition the drilled cuttings tend to settle out of the drilling mud. Nevertheless, the presence of low specific gravity polymer beads in the drilling mud has improved the CTR by $9 \%$ because they produced buoyancy forces in the drilling mud system. Also, the drilling mud's flow momentum made the cutting to be transported more efficiently. It is obvious that the $50^{\circ}$ hole inclination was critical because the cuttings bed has the tendency to slide continually and tumble down which would increase the hydraulic requirement for adequate hole cleaning. It should be noted that this experimental work complemented the findings published by Onuoha et al. [2].

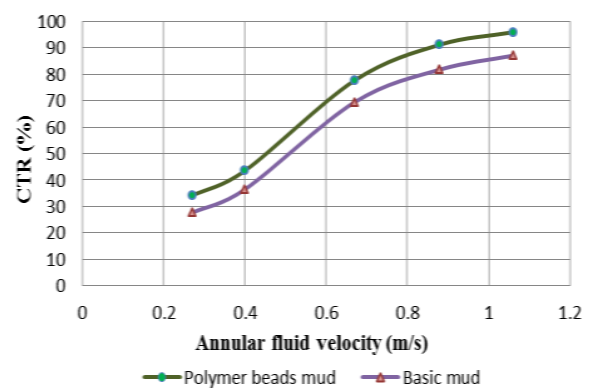

(a)

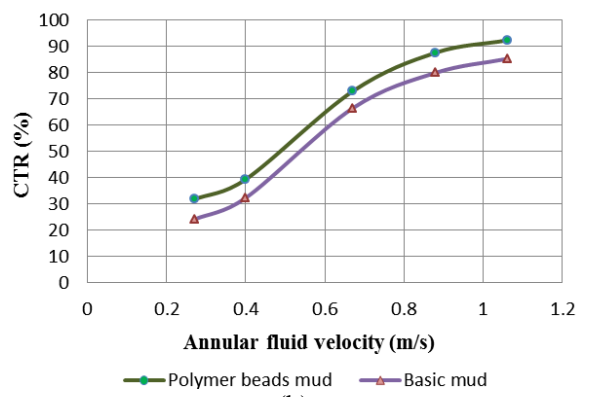

(b) 


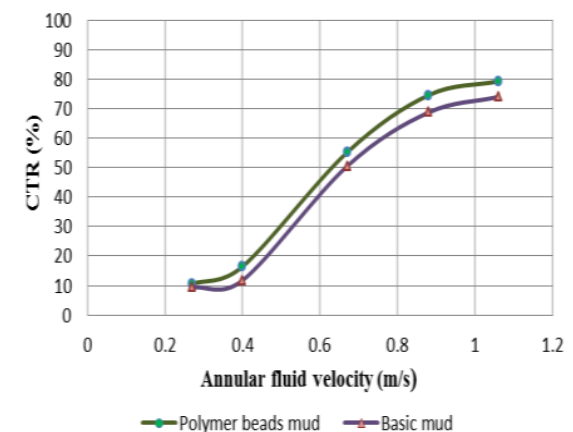

(c)

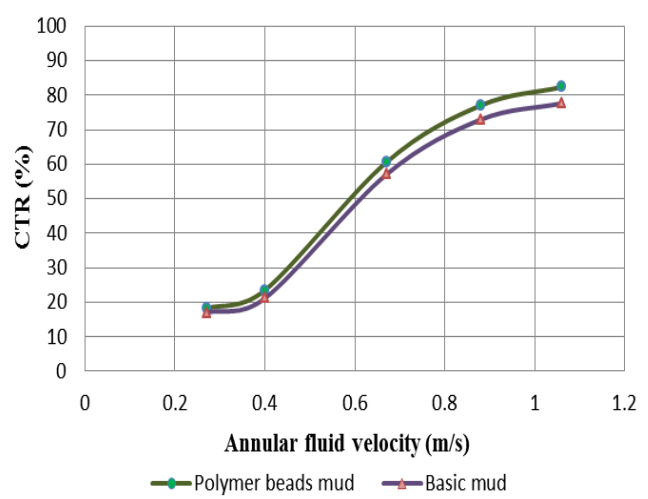

(d)

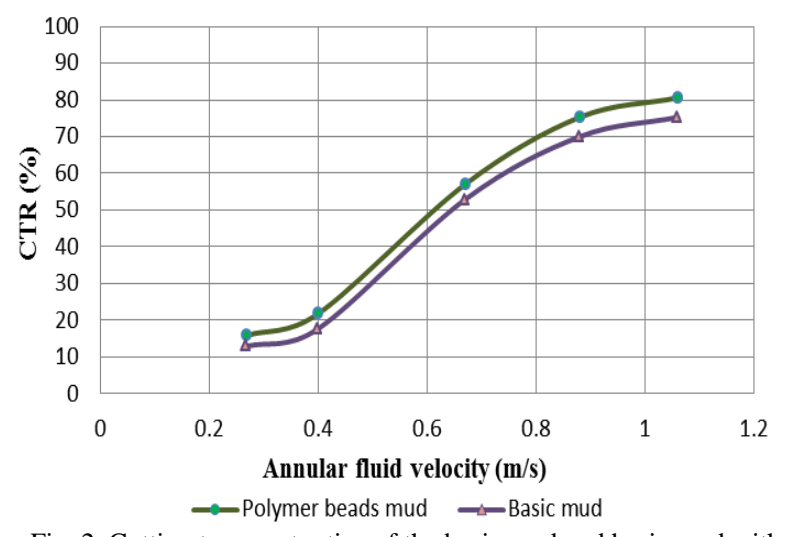

Fig. 2. Cutting transport ratios of the basic mud and basic mud with polymer beads at various inclination angles: (a) $0^{\circ}$ (vertical), (b) $30^{\circ}$, (c) $50^{\circ}$, (d) $70^{\circ}$, and (e) $90^{\circ}$ (horizontal).

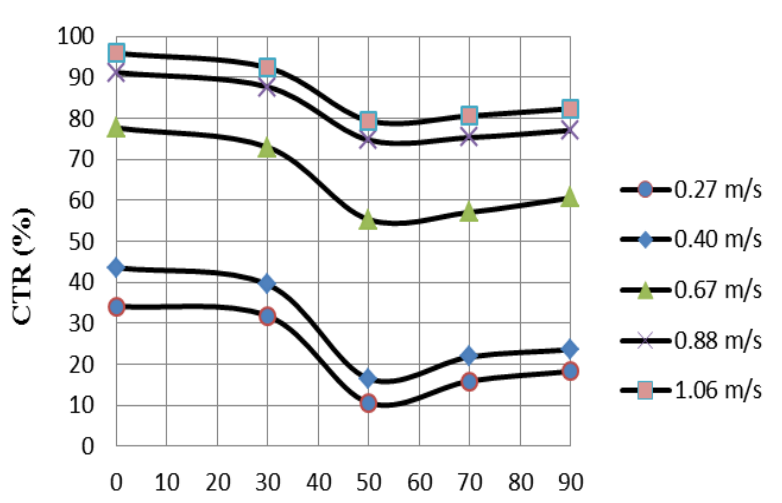

Hole inclination (deg)

Fig. 3. Cuttings transport ratio versus hole inclinations at different mud flow velocities.

\section{CONCLUSION}

Cuttings transport efficiency is a direct function of annular mud velocity, and is largely reliant on the characteristics of the annular mud velocity's profile. Obviously, increasing annular mud velocity of both mud systems would improve the hole cleaning, in both laminar and turbulent flows. The presence of polypropylene-based polymer beads in water-based mud would have further positive effects on hole cleaning, i.e., improve cuttings removal by $5 \%$ in a laminar flow and $9 \%$ in a turbulent flow as compared to basic water-based mud. Nevertheless, the CTR decreases as hole inclination increases from vertical to horizontal. The $50^{\circ}$ hole angle appears as the critical angle because cuttings' bed sliding tendency has higher chances to occur. Consequently, an increase in hydraulic power is needed for an effective wellbore cleaning.

\section{ACKNOWLEDGMENT}

The authors would like to express their gratitude to the Research Management Center of UTM and the Malaysian Ministry of Higher Learning for their support and permission to publish this paper.

\section{REFERENCES}

[1] K. Wang, T. Yan, X. Sun, S. Shao, and S. Luan, "Review and analysis of cuttings transport in complex structural wells," J. Open Fuels \& Energy Science, vol. 6, pp. 6-9, Dec. 2013.

[2] M. D. U. Onuoha, I. Ismail, A. Piroozian, N. S. Mamat, and A.S Ismail, "Improving the cuttings transport performance of water-based mud," Sains Malaysiana, vol. 44, no. 4, pp. 629-634. April, 2015.

[3] M. N. Bilgesu and G. A. Chukwu, "Experimental study of the parameters affecting cuttings transport in a vertical wellbore annulus," presented at the Western Regional Meeting, Long Beach, California, Mac. 23-25, 2007.

[4] M. Q., S. Duan, M. J. Miska, N. Yu, and T. R. Ahmed, "Transport of small cuttings in extended reach drilling," SPE Drilling \& Completion, vol. 23, no.3, pp. 258-265, Sep. 2008.

[5] P. Ali, I. Issham, Y. Zulkefli, B. Parham, and S. Ahmad, "Impact of drilling fluid viscosity, velocity and hole inclination on cuttings transport in horizontal and highly deviated wells," J. Petrol. Explor. Prod. Technol., vol. 2, no. 3, pp. 149-156, August 2012.

[6] A. Z. Noah, "Optimizing drilling fluid properties and flow rates for effective hole cleaning at high-angle and horizontal wells," J. Applied Sciences Research. vol. 9, no. 1, pp. 705-718, 2013.

[7] T. R. Sifferman and T. R. Becker, "Hole cleaning in full-scale inclined wellbores,” SPE Drilling Engineering, vol. 7, no. 2, pp. 115-120, June 1992.

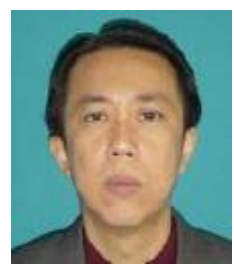

I. Ismail is from Malaysia. He works as an academic staff at Department of Petroleum Engineering, Universiti Teknologi Malaysia (UTM). He is the holder of Master in Petroleum Engineering from Imperial College of London.

Prior to working as an academician for more than 25 years with UTM, he worked as a field engineer with Amsito Oilwell Services. His research area includes drilling fluids, formation damage, well completion, and two-phase flow. Associate Professor Ismail is a chartered engineer of Imarest and UK Council. He has authored two books on well completion and produced many articles in journals. He is a member of review board for International Journal of Research in Engineering and Technology.

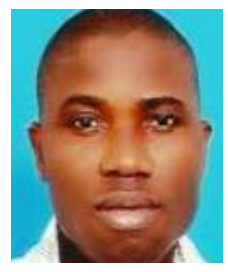

M. D. U. Onuoha is from Nigeria and he was a master graduate in petroleum engineering from Universit Teknologi Malaysia in 2014. His research interest covers drilling fluids and formation damage. $\mathrm{Mr}$. Onuoha is currently pursuing his $\mathrm{PhD}$ study in offshore engineering at China University of Petroleum Beijing. 


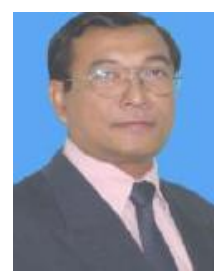

A. R. Ismail is from Malaysia. He is an academic staff of more than 30 years at Petroleum Engineering Dept. of Universiti Teknologi Malaysia. He received his M.Phil. (Petroleum Eng.) from Heriot-Watt University, UK. His research interest includes drilling fluid, shale problem, and formation damage.

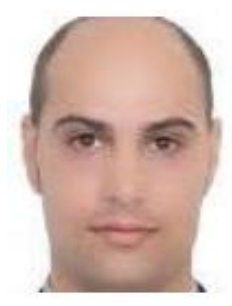

A. Piroozian is from Iran. He is a master petroleum engineering graduate of Universiti Teknologi Malaysia (UTM) in 2010. His research interest covers drilling and production engineering majoring in two-phase flow. Currently, Mr. Piroozian is pursuing his $\mathrm{PhD}$ on waxy crude oil-water two-phase flow in pipe in UTM.

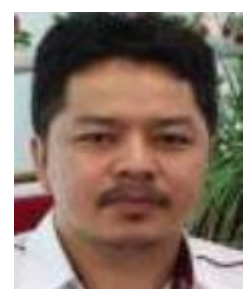

W. R. Wan Sulaiman is from Malaysia and $\mathrm{He}$ is a petroleum academic staff with Universiti Teknolog Malaysia (UTM). He is the holder of $\mathrm{PhD}$ in Chemical Engineering from Dongguk University, Seoul, South Korea.

Dr. Wan Sulaiman has been serving UTM for more than 10 years. He is a chartered engineer of Imarest and UK Council. His research area includes reservoir published many papers in international journals

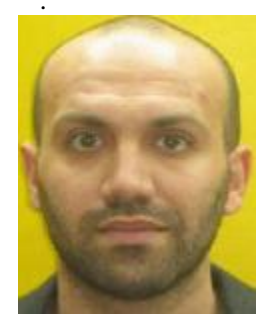

S. M. Abbda is a Libyan. He was a master graduate in petroleum engineering from Universiti Teknologi Malaysia. His research interest covers drilling engineering. Currently, he is working with an oil company in Libya. 